\title{
Research on the Informal Institutional Changes' Impact on the Governance of the Small-scale Rural Public Resource-Taking the Well Governance of $L$ Village as an Example
}

\author{
Li-Rong Zhong ${ }^{1, a}$, Yong-Zhong Yang
Ming-Hua Lin ${ }^{1, a, \star}$, Bi-Hui Xie \\ ${ }^{1}$ Business School of Sichuan University, Chengdu, 610065 \\ ${ }^{2}$ Agricultural Bank of China Longyan City Branch, Fujian, 364000 \\ ${ }^{3}$ School of Economic \& Management, Sichuan University of Science \& Engineering, Zigong, 643000 \\ a1490925990@qq.com, ${ }^{b} 383129027 @ q q . c o m$, 'rodin8481@163.com, ${ }^{d} 584165615$ @qq.com \\ ${ }^{*}$ Corresponding author
}

Keywords: Small-scale public resources, Governance, Evolutionary game, Informal institutional change.

\begin{abstract}
The lack of property rights of China's rural small-scale public resources results in excessive use, and even exhaustion of public resources. Based on this, the paper takes Ostrom's game model of public resources for reference and uses evolutionary game theory tools to analyze the influential factors of public resources in the rural informal institutional change, and then makes the research on the impact of the informal system changes on the governance of public resources. It reveals that: without the impact of external factors, the cooperative behavior that utilizes resources under the guidance of the informal institutions is stable and sustainable. While the impact of external factors such as water resource price, resources accessible technology and social cohesion existed, the informal institutions that constraint people's behavior may be broken, resulting in overall reduction of the stock of long-term resources, or even exhaustion. So the paper holds that: it is of great necessity to focus on the role of the informal system in the governance of rural small-scale public resources, but the guidance of the government should be considered when the conditions are not mature.
\end{abstract}

\section{Introduction}

The prisoner's dilemma, the tragedy of the commons and collective action difficulties and other theoretical models in the theories of public goods are all illustrated that the individual rational action in public choice ultimately leads to the non-rational action of the public. Based on this, the paper is concerned with what factors would lead to the change of informal system of self-governance? What the impact is on the public resource governance? For public resource governance, Ostroms(2000) creatively put forward the self governance theory[1] which shows that users can solve resource system changes and a series of problems in certain conditions by themselves, thus created a new system analysis method. Chinese scholars such as $\mathrm{Hu}$ Yang (2001) and Li Wu xuan (2002) and Liu Zhenshan also took self governance theory as the foundation and proposed new ideas to solve the common pool resources problems to realize system innovation and pointed out that self governance theory for public resources in our country especially provide a good guidance of sustainable use of renewable resources. But self governance theory problems also exist applicable limitations in our country. Zhang Xin (2008), Gao Xuan (2009), Zhang Zhenhua (2010) pointed out several limitations of self governance theory in China when commenting on self governance theory: (1) limited analysis of the informal system; (2) the limited applicability of the political system ; (3) the limited nature of the citizen consciousness. [2] We can see that the Chinese public resources autonomous conditions are not ripe thus the game model of public resources of Ostrom has many unreasonable places in the analysis of public resources in china. On the other hand, many researchers used game theory from the micro perspective to explore the rule of system's 
generation and change. [3]Aoki's evolutionary game system theory (2001) was based on the bounded rationality hypothesis [4] and it provided favorable theoretical evidence for diverse systems, and also part of the reason for the institutional change. [5]

This paper proceeds into four sections: the second section establishes and analyzes the public resource management evolutional model. The third section presents the empirical analysis of L village well's governance, while the last section concludes and suggests.

\section{Organization of the Text}

\section{Introduction the Evolutionary Game Model of Public Resource Governance}

Ostrom et al used N static game model in the experiment research of public resources in 1992. Suppose that $\mathrm{N}$ members have perfect rights entering or exiting some public resources. There are some problems about assuming in the infinitely repeated game model, therefore, it takes the evolutionary methodology based on infinite repeated model to replace it. According to the state of the resources, it establishes the evolutionary game model under the conditions with both static resources and dynamic resource.

\section{The evolutionary game model of static resources}

The model assumptions:

(1) Supposing that there are $\mathrm{N}$ game players, the group members' benefit is common knowledge, but they will change their strategies of basic economy viewpoints according to different benefits.

(2) Using $\mathrm{X}_{\mathrm{i}}$ represents the labor of the access of member $i$ to resources in the unit time, suppose here only two kinds of labor input level, low input level $\mathrm{x}_{1}$ and high input level $\mathrm{x}_{\mathrm{h}}$. All members' total labor is denoted by X.

(3) Assuming that the stock of resources is static namely $\mathrm{K}=\mathrm{K}_{0}$, with the total number of access to resources in unit time using $\mathrm{H}(\mathrm{X}, \mathrm{K})$ said.

(4) Assuming that group members can choose from three strategies including cooperators ( $\mathrm{C}$ comply with resource usage rules), defectors (D that does not comply with resource usage rules) and enforcers (E), at some point the next member can only adopt a pure strategy of the three. Make $s_{1}, s 2$, s3 respectively representative of the groups' share of cooperators, defectors and defectors.

(5) Assuming that the labor cost can be expressed as W, it can represent the hired wages or opportunity cost, we use it here as a constant and exogenous variables.

(6) Each person in the group can be assumed to punish other defectors of members. Assuming the former to pay cost of implementation $\gamma$, and the latter to suffer losses $\delta$,

(7) Assuming that $\pi_{i}$ is used to denote the net income of member i gained in resources in unit time, $\mathrm{k}_{\mathrm{i}}$ represents the number of members making punishment on the member $\mathrm{i}, \mathrm{l}_{\mathrm{i}}$ is the number of members be punished by member $\mathrm{i}$.

The solution of the model:

Proposition 1[6]: according to the above assumptions, the game in the use of public resources has only one Nash equilibrium, which is inefficient to the labor input, and would result in the overuse of the public resources.

Introducing behavioral inertia in the group members' response to higher profit, here we consider a simplified model without considering the continuity of labor input levels, at any point of time, assuming a certain type of member' ratio is $s_{i}$. It can be simplified using Replicator dynamics to describe this evolution movement (Peter and Leo, 1978):

$$
S_{i}=s_{i}\left(\pi_{i}-\bar{\pi}\right), \quad i=1,2,3
$$

$\pi=\sum \mathrm{s}_{\mathrm{i}} \pi_{\mathrm{i}}$ is the average benefit of all group members. The dynamic system constant equilibrium is when to all members of the $\mathrm{i}$-th meet a state of $\mathrm{s}_{\mathrm{i}}=0$. Finally, we get the following two element systems: 


$$
S_{i}=s_{i}\left(\pi_{i}-\bar{\pi}\right), i=1,2
$$

The necessary and sufficient condition for a state to become a dynamic system (2) is that all the surviving strategies have equal earnings. The next will prove that this state is unstable. [7]

Proposition 2: for all its parameters D-equilibrium gradually approaches the stable state. If $\delta \mathrm{n}>\left(\mathrm{x}_{\mathrm{h}}-\right.$ $\left.\mathrm{x}_{1}\right)\left(\mathrm{A}\left(\mathrm{n}_{\mathrm{l}}\right)-\mathrm{w}\right)$ then a subset of stable point of $\mathrm{s}$ in C-E unity forms a non empty interval: $\xi=\left\{\left(s_{1}, s_{2}\right) \mid 0 \leq s_{1}<\bar{a}, s_{2}=0\right\}$, and $\overline{\mathrm{a}}$ is a positive number less than 1 . $\mathrm{A}(\mathrm{X})$ represents profit. For each $\mathrm{s}$ in interval $\xi$, the existence of its neighborhood makes any initial trajectories in this neighborhood will eventually gradually close to the spacing of $\xi$. Others are not constant point (steady state). [8]

\section{The evolutionary game model under dynamic resource}

The model assumptions:

(1)Supposing that there are $\mathrm{N}$ game players, the basic economy viewpoint is that members will change their policy according to the different benefit.

(2) Assuming that the level of labor input $x_{l}(K)$ and $x_{h}(K)$ is continuous. Therefore, violator's labor input

for mining resources is : $X\left(s_{2}, K\right)=\left(1-s_{2}\right) x_{1}(K) n+s_{2} x_{h}(K) n$.

(3) Assuming that the resources is dynamic, making Resources remnant $\mathrm{K}$ endogenous. We can use micro function $G(K)$ to describe the regenerative ability of natural resources. With the exploitation of resources taken into account, the dynamic change of resource stock can be expressed as: $\mathrm{K}=\mathrm{G}(\mathrm{K})-\mathrm{H}(\mathrm{X}, \mathrm{K})$.

The solution of the model

Let Kmin be a minimum of resources stock available. Let $\mathrm{x}_{\mathrm{E}}(\mathrm{K})$ denote all members' optimal level of average labor input under the static case, labor input levels of $\mathrm{x}_{\mathrm{N}}(\mathrm{K})$ denote the Nash equilibrium under the stock of resources K.

Therefore, total labor input for resource exploitation of violator is:

$$
\mathrm{X}(\mathrm{s} 2, \mathrm{~K})=(1-\mathrm{s} 2) \times \mathrm{l}(\mathrm{K}) \mathrm{n}+\mathrm{s} 2 \mathrm{xh}(\mathrm{K}) \mathrm{n}
$$

With the dynamic replication function, we can make a three-element dynamic system, in which three variables are: $\mathrm{s}_{1}, \mathrm{~s}_{2}$ and $\mathrm{K}$. At any case of $K_{L}<K<K_{M}, \mathrm{G}(\mathrm{K})>0$. And $\mathrm{K}=0$ when putting enough resources to obtain a large amount of labor that can offset the natural recovery quantity. Let $\hat{X}(K)$ denote total labor input when $\mathrm{K}=0$.

Proposition 3: In the level of resources corresponding to $\mathrm{K}$, if $X_{h}^{\prime}(K)>\hat{X}^{\prime}(K)$, then any defectors equilibrium is asymptotically stable. If $X_{h}^{\prime}(K)<\hat{X}^{\prime}(K)$, the equilibrium is unstable. [9]

Proposition 4: if stable defector equilibrium exist here, the existence of a $\mathrm{C}$-E unity equilibrium in a higher resource stock level. Furthermore, if the $\delta n>\left(x_{h}-x_{l}\right)(A-w)$ and $\hat{X}^{\prime}(K)<0$ in the corresponding resource stock level has C-E unity, there will be nonempty set $\xi$ of the unity where that every point $\mathrm{s}$ inside the dynamic system $(\mathrm{s}, \mathrm{K})$ is consistent with the steady state inside.

The above propositions reveal that if there exists a stable equilibrium only containing defectors, then the equilibrium including both cooperators and enforcers can exist in a higher resources stock level.

\section{Empirical analysis about the Informal Institutional changes' Effect on the Public Resource Governance}

\section{Overview of L Village}

L village is a certain county with about 500 households in the south of Longyan city, western Fujian province. People have been taking around 50 households as a unit group, and dig a well for water nearby 
(the water getting manner consistent with Ostrom's definition of small scale public resources). With the completion of the cement road traffic at the beginning of 2000, the economic exchanges become more frequent. Before 2000, the well mainly provided daily water according to the average need allocation of water resources, which formed the punishment rules mainly by fines, blame and group alienation. After 2000, with transportation becoming convenient, the consumption of water resources increased substantially. The fetching water technology changed from artificial ways to pump. Before 2003, the well water could still manage to support life and production water, but the original order of taking water disappeared. After 2003, the scale of production activities gradually expanded a variety of production and processing activities often cannot be carried out normally because of the lack of water; community members often invade other groups for water resources.

According to the changes of the system, it can be divided into the following three stages:

\section{An empirical analysis of water governance in $L$ Village}

The empirical analysis of water management in $\mathbf{L}$ Village before $\mathbf{2 0 0 0}$. Before 2000, the well is enough for people's daily life. We assume that the water is static. The informal institution is the system maintaining a shared belief which is represented by the evolutionary equilibrium namely as relatively stable D-equilibrium or C-E equilibrium.

In stable state. It depends on the values of the parameters in the model. The length $\xi$ of the collection in Steady state can be expressed by the following formula:

$$
1-\frac{\left(x_{h}-x_{l}\right)\left(A\left(n x_{l}\right)-w\right)}{\delta n}
$$

Assuming that the above expression is non negative, then there is no cooperators equilibrium can exist. So when $\delta n$ reduces, the size of the collection of steady state will also be reduced, when $\delta n$ reduces small enough, the steady state set will completely disappear.

Analysis of the informal institutional evolution of water resources under the static state (20002003). During 2000 to 2003, assuming that water resource is static, then we discuss what factors lead to break the game equilibrium of informal institution. The decrease of $\delta n$ and the increase of $\mathrm{A}(\mathrm{X})$ lead to the decrease of $\xi$, when the $\mathrm{X}$ reduces enough, the balance is broken. At least two reasons lead to the increase of $\mathrm{A}(\mathrm{X})[10]$ : promotion of technology for access to resources and the increase of resource price. Because the function of the extent of penalty in this section is not obvious, thus we firstly study the effect of mining resources net profit increase: After 2000, due to the development of economy in L village, market price of water resources increases and technology progress makes the labor more efficient, namely $\mathrm{A}(\mathrm{X})$ improves. When the reduction degree is large enough, then the game equilibrium is broken, the informal institutional change results in the disruptions of the water resources order.

Analysis on the informal institutional evolution of water resources under the dynamic state (after 2003). After 2003, we consider the water resources dynamic. The analysis concentrates on the effect that the decrease of punishment level and invasion of foreign members have the informal institutional change and the effect on the stock of the water resources when input labor marginal revenue is more than the wage level $\mathrm{w}$ under the smallest available resources level. The punishment $\delta n$ usually uses the local form. There is basically no loss when a member of the group is rejected by the villagers in $\mathrm{L}$ village and the surrounding areas exchange frequently. Thus $\delta n$ greatly reduces which results in the decreases of the stable state set length $\xi$. And it may lead to the informal institutional change when reduced to a certain extent. Moreover, the intrusion of other group members outside for water resources leads to the reduction of the length of the stable state collection $\xi$. If the social rules guiding people to labor input are formulated based on that of the whole group, then with the increase of $\mathrm{N}, \mathrm{nx}_{1}$ remains unchanged, while $\left(\mathrm{x}_{\mathrm{h}}-\mathrm{x}_{1}\right)$ becomes larger which will decrease the length of the $\xi[11]$, however if $\mathrm{x}_{1}$ don't change with $\mathrm{N}$, then $\mathrm{A}\left(\mathrm{nx}_{\mathrm{l}}\right)$ will decrease which will cause the decline of profit obtained from defectors. Finally, the informal institution will change.

Here the public resources model has the following characteristics: if there is a decentralized and costly punishment, constraints of resources use and sanction violations of social rules which can ensure that the 
group members are not driven by self-serving behavior, so as to achieve a stable state to cooperate in the development of the use of resources, the steady state contains the rules of society defined as the informal system.

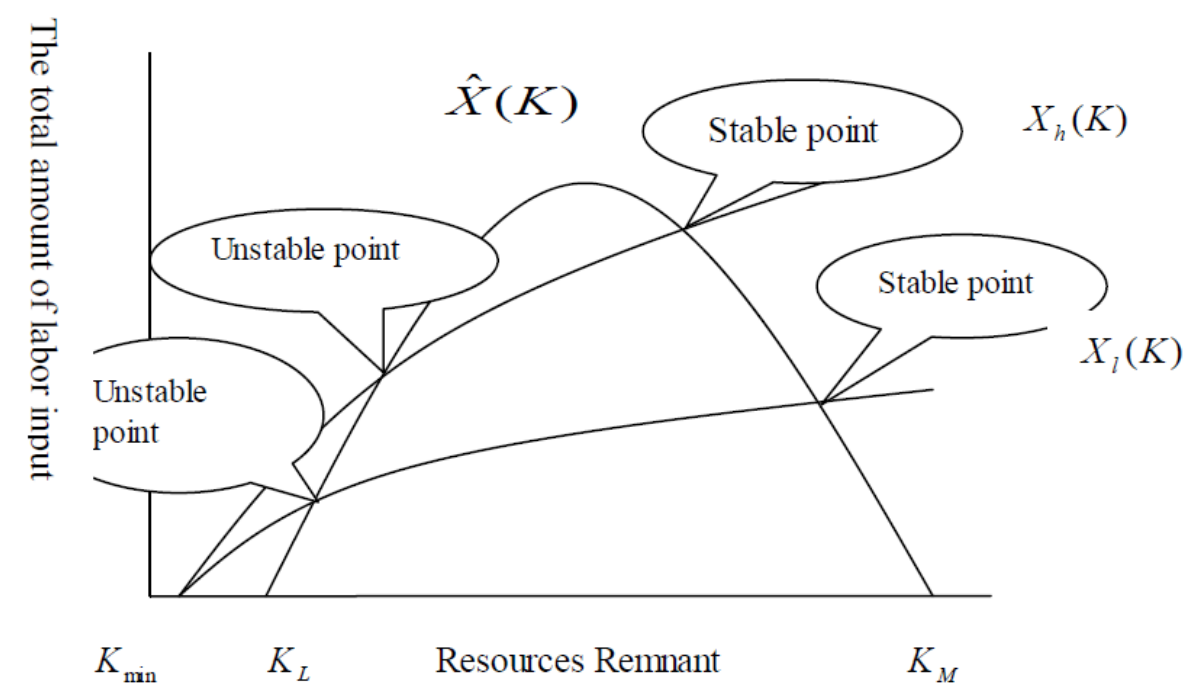

Fig. 1 Marginal revenue more than wages w

\section{Conclusions and suggestions}

Pay attention to the function of the informal system have on public resource governance

Chinese rural institutional environment can be summarized as the social economy is in transition from traditional to modern period, therefore, the institutional arrangements of rural needs both the formal system and informal system. In rural small-scale public resource governance, we should pay full attention to the role of the informal system.

On the one hand it's necessary to strengthen the construction of villagers' autonomy system and lays a good foundation for the system to play the role, and also provides the basic condition for the combination of the formal system and informal system in the countryside. On the other hand we should guide the informal institutional change. [12] It should thoroughly study the influence of informal institution and its changing tracks following the bottom-up principle, and then minimize the cost and resistance of rural informal institutional change in the rural reform.

The government should play the role of guidance

First of all, we should promote the transformation of government functions to make clear the government departments' responsibilities in the villagers' self-governance, and transfer a part of social functions to community, which cannot be escapable. Secondly, we should renovate the concept of governance and establish the scientific concept of development. The existing problems of rural small-scale public resources should not be ignored just for its slight impact on the economic constructions and political performance. Finally, we should straighten out the relationship between the government and the society, and then cultivate the social self-governance organizations, which mean to return most social affairs governance rights to social organizations, but the government should also give some guidance on the governance of public resource affairs.

\section{Acknowledgements}

We gratefully acknowledge the research support received from the National Natural Science Fund (71173150), the Key Project of the National Social Science Fund (12AZD018), Program for New Century Excellent Talents in University (NCET-12-0389) and Research Center of Folk Culture for Key Research Base of Philosophy and Social Science in Sichuan Province (MJ14-15).

\section{References}

[1] Yoram Barzel, A Theory of the State, Cambridge University Press., New York, 2002, pp.114. 
[2] Michael Mcginnis, Polycentricity and Local Public Economies, Shanghai Joint Publishing, Shanghai, 2000, pp.101.

[3] Govindan and Wilson, Uniqueness of the index for Nash equilibria of two-player games, Economic theory. 10(1997)541-49.

[4] Young, Peyton, Individual Strategy and International Journal of Game Theory, (1998)73-80.

[5] Jang Nengwen, A Review of the Lift, the Collective Action and the National Rise and Fall of Olsen Theory of Collective Action, Academic forum.11( 2009).

[6] Xu Datong, Some Thoughts on National Political Culture, Tianjin Normal University Journal .4(1998).

[7] Mao Fei. Multi Center System Arrangement: A New Idea to Solve the Problem of the Relationship between Rural, Journal of Chengdu Institute of Public Administration.9 (2003).

[8] Wang Xinglun, Multi Center Governance: A New Theory of Public Management, Journal of Jiangsu Administration Institute. 1(2005).

[9] Dai Wenbiao, New Theories on Public Economics, Zhejiang University Press, Hangzhou, $2005,9$.

[10] Shen Chengcheng, From Government Monopoly to Multi Interaction, Truth Seeking.3 (2006).

[11] Guo Yongfang, Thoughts on the Development of Rural Public Utilities, Chinese Public Administration.6 (2007).

[12] Liu Xirui, Li Yanling, System Innovation of the Rural Public Affairs Governance, Journal of Tianjin Administration Institute.1 (2007). 